\title{
A Survey of Occupational Therapy Practitioners in Mental Health
}

Christine Craik MPhil, DMS, Dip COT, MIMgt, SROT

Director of Undergraduate Occupational Therapy Studies, Brunel University, John D Chacksfield Dip COT, PGCE, SROT

Chairman, Association of Occupational Therapists in Mental Health

Gabrielle Richards BAppScOT, MScIHWS, SROT

Practice Development Tutor

Bethlem \& Maudsley NHS Trust

\section{Key Words}

Mental Health

Psychiatry

Staff

Christine Craik MPhil, DMS, Dip COT, MIMgt, SROT

Director of Undergraduate Occupational Therapy Studies, Brunel University, Osterley

Campus, Borough Road, Isleworth, Middlesex,TW7 2DU.

christine.craik@brunel.ac.UK

Chairman of Mental Health Project Working Group of the College of Occupational Therapists

\section{ABSTRACT}


As part of the College of Occupational Therapists' Mental Health Project, a survey of occupational therapists practising in mental health in the UK was conducted. A questionnaire was sent to 200 members of the Association of Occupational Therapists in Mental Health and achieved a $68.5 \%$ response rate.

The majority of the 137 respondents were female, with Senior I staff between 20 and 30 years of age who were unlikely to have worked in another area forming the largest group. Although most had received additional training, they identified the need for more training, especially in aspects of occupational therapy. Most were managed by an occupational therapist and $96 \%$ received supervision. Community mental health was the most frequently reported area of work with leisure, counselling, anxiety management and creative activities the most frequently used interventions. Respondents were committed to the core principles of occupational therapy and the need to develop outcome measures and evidence based practice, and were concerned about moves to generic working.

This study has provided data, not only for the position paper on the way ahead for occupational therapy in mental health but also for individual occupational therapists and managers. 


\section{INTRODUCTION}

To consider the future of research, education and practice in occupational therapy in mental health, the College of Occupational Therapists established a working party. As the foundation for a position paper, a review of the literature on occupational therapy in mental health over the past 10 years was conducted (Craik, 1998). The review established that little had been published in the UK about the profile of the profession and its practitioners, or about the interventions they employed in mental health, although subsequent articles have studied the interventions used by occupational therapists in community mental health teams. (Meeson, 1998 a, b) From the literature it appeared that occupational therapists concentrated on four clinical areas dementia; work rehabilitation; community mental health and forensic psychiatry. (Craik, 1998)

There has been concern in the USA about the position of occupational therapy in mental health, with declining numbers of therapists noted (Bonder, 1987, Kleinman 1992, Paul, 1996). In 1986, Barris and Kielhofner surveyed educators who suggested the major problems in mental health were deficiencies in role definition, unifying theory and research validating the profession. In Australia, Bartlow and Hartwig (1989) examined the status of practice, methods of assessment and frames of reference in mental health. They surveyed 136 practitioners achieving a $65 \%$ response rate, and found that there was no consensus about the pattern of service delivery based on theoretical principles, scope of practice or the use of assessments. More recently in the UK, Job et al (1997) noted that there had been little documented about mental health practice.

\section{AIMS OF THE SURVEY}


As other aspects of the Mental Health Project proposed to study occupational therapy managers and educators, this survey focused on practitioners in mental health and aimed to:-

1. Determine the profile of occupational therapists practising in mental health in the UK

2. Identify the situations in which occupational therapy in mental health was practised

3. Ascertain the assessments and interventions used by occupational therapists in mental health

4. Identify current and future issues of importance to occupational therapy in mental health

\section{METHOD}

To obtain this data a survey methodology was chosen. A questionnaire was designed in response to the literature, the aims of the project and the views of 13 occupational therapists who responded to invitations to contribute to the project. The questionnaire elicited information on the profile of the practitioners, their responsibilities, professional development, employment situation and their opinion of the issues facing occupational therapy.

\section{Pilot}

The questionnaire was piloted at the Annual Conference of the College of Occupational Therapists in 1997 at a workshop advertised as part of the consultation process of the project. The 33 participants completed the questionnaire had been 
informed that it was anonymous, although their names were known and they would be excluded from the final survey. Following the analysis of the pilot questionnaire some minor changes were made to produce the final version.

\section{Sample}

In the absence of alternative methods of identifying occupational therapists practising in mental health, the assistance of the Association of Occupational Therapists in Mental Health (AOTMH) was enlisted. From their 460 members, those identified as students, educators, managers at Head 1 and above and support staff were excluded as they were not the focus of this study. Also excluded were those who participated in the pilot study leaving 400 members from all areas of the UK. Due to the constraints of time and resources, a questionnaire was then sent to every second person remaining on the list. Thus, 200 questionnaires were sent with a covering letter and a stamped addressed envelope.

\section{RESULTS}

Of these questionnaires one was returned indicating a wrong address, one was returned not completed as the recipient was no longer worked in mental health and 137 were returned and analysed, representing a $68.5 \%$ response rate. The results were analysed using the Statistical Package for Social Scientists (SPSS) and content analysis. The most relevant results are presented here in three sections: profile of the occupational therapists, employer profile and occupational therapy in mental health. 


\section{Gender}

Of the 137 respondents, $130(95 \%)$ were female and 7 (5\%) were male.

\section{Age-Group and grade of Post}

All respondents indicated their age-group with the largest group 51(37\%) being in the 20 - 30 year age-group. Respondents indicated the grade of their current post using the Whitley Council Scale with the largest group of 59 (43\%) therapists being at Senior 1

grade. Four occupational therapists had an alternative title and six therapists had an additional title. The results are displayed in Fig 1

Fig 1 Age-Group and grade of post

\section{Occupational Therapy Qualification}


One hundred and two (75\%) therapists had a Diploma of the College of Occupational Therapists, $32(23 \%)$ had a Bachelor of Science or Bachelor of Science with Honours Degree in Occupational Therapy and three had a post Graduate Diploma in Occupational Therapy.

\section{Time Worked in Mental Health}

All respondents reported how long they had worked in mental health and in their current post. Fifty-three (39\%) having worked in mental health for less than five years, and $93(68 \%)$ had worked in mental health for less than 10 years. When time in their current post is considered $112(82 \%)$ therapists had been there less than 5 years, with $32(23 \%)$ less than one year. The results are displayed in Fig 2.

Fig 2 Time Worked in mental health and in current post

\section{Experience Other than Mental Health}


The majority of respondents, 74 (54\%) reported working only in mental health. Of the remaining 63 therapists, $45(71 \%)$ had worked for 2 years or less with several indicating that the post had been rotational. Forty-five of 63 respondents $(71 \%)$ had worked in physical disabilities. The results are displayed in Table 1.

Table 1 Number of years worked in areas other than mental health

\begin{tabular}{||l|r|r|r|r|r||}
\hline & \multicolumn{5}{|c||}{ NUMBER OF YEARS } \\
\hline AREA & $>1$ & $1-2$ & $3-5$ & $<5$ & TOTAL \\
\hline $\begin{array}{l}\text { Physical } \\
\text { Disabilities }\end{array}$ & 12 & 22 & 9 & 2 & $\mathbf{4 5}$ \\
\hline $\begin{array}{l}\text { Social } \\
\text { services }\end{array}$ & 4 & 1 & & 1 & $\mathbf{6}$ \\
\hline $\begin{array}{l}\text { Learning } \\
\text { Disabilities }\end{array}$ & 1 & 5 & 3 & 3 & $\mathbf{1 2}$ \\
\hline Total & $\mathbf{1 7}$ & $\mathbf{2 8}$ & $\mathbf{1 2}$ & $\mathbf{6}$ & $\mathbf{6 3}$ \\
\hline
\end{tabular}

\section{Reasons for Working in Mental Health}

Asked in an open question, what factors attracted them to work in mental health, 130 (95\%) therapists replied; of these 119 made two or more points, producing a total of 355 points. These represented a diverse range of factors which were examined for similarities and four main clusters identified.

The largest cluster, with 55\% of the points, concerned the nature of the clinical work including the variety and diversity of the work and clients; the wide range of clinical skills and approaches used; the interpersonal aspects and time to develop a deeper relationship with clients; the uncertainty and challenge of the work and need for flexibility and creativity by the occupational therapist. 
The working environment, with $27 \%$ of the points, formed the second cluster with respondents valuing the work as being more interesting and rewarding; providing greater job satisfaction and enjoyment; having greater informality; allowing closer working with colleagues; and providing more support autonomy and scope for creativity in applying occupational therapy.

The third cluster with $11 \%$ of the points noted, related to personal factors such as previous experience, particularly as a student or support worker, and personal interest or aptitude, for example 'it is the only area I have ever wanted to work in - that is why I trained as an occupational therapist'

The final cluster with $7 \%$ of the points concerned the role of the occupational therapist in mental health; in particular the opportunities to develop the role locally; being true to the philosophy of occupational therapy; including treatment as well as assessment; being 'able to complete the whole occupational therapy process' and having a unique and important role.

\section{Additional Training}

In an open question, $125(91 \%)$ respondents gave examples of additional training, indicating the name and length of courses attended. This produced a large quantity of diverse data because most respondents had attended more than one course, with several attending many courses. Courses were categorised into those conferring qualifications according to the highest level of qualification and those which did not lead to qualifications which were divided into short, up to two weeks duration and long, those of several weeks or day release over a number of months. Thus each 
respondent was included in only one category. The largest category was short courses with $57(46 \%)$ therapists, while 35 (28\%) therapists had completed a course leading to qualification. The results are displayed in Table 2.

\section{Table 2 Additional Training}

\begin{tabular}{||l|r|r||}
\hline COURSE & N0 & \% \\
\hline Master's & 9 & 7 \\
\hline Bachelor's & 5 & 4 \\
\hline Diploma & 10 & 8 \\
\hline Certificate & 11 & 9 \\
\hline Long & 33 & 26 \\
\hline Short & 57 & 46 \\
\hline Total & $\mathbf{1 2 5}$ & $\mathbf{1 0 0}$ \\
\hline
\end{tabular}

\section{Current occupational therapy training needs}

In an open question, 120 respondents (88\%) identified their current most important occupational therapy training need. Twenty-four identified more than one need creating a total of 148 responses, not all of which were occupational therapy specific. They were arranged into six clusters with the largest relating to new aspects of occupational therapy such as outcome measures; evidence based practice and research. The second cluster consisted of generic clinical topics related to mental health such as cognitive behaviour therapy and anger management. The third cluster related to updating previous occupational therapy knowledge and skills; 'developing expertise in core skills' and 'refresher in assessment tools and models'. In the management cluster, promotion and marketing were featured and in the policy cluster, risk management was emphasised. The two clusters related to occupational therapy represented $47 \%$ of the identified training needs. The results are summarised in Table 3 


\section{Table 3 Occupational Therapy Training Needs}

\begin{tabular}{||l|r|r||}
\hline TOPIC & No & \% \\
\hline New aspects of O T & 44 & 30 \\
\hline Generic clinical aspects & 32 & 22 \\
\hline Updating O T & 26 & 17 \\
\hline Management & 25 & 16 \\
\hline Policy issues & 14 & 10 \\
\hline Fieldwork education & 7 & 5 \\
\hline TOTAL & $\mathbf{1 4 8}$ & $\mathbf{1 0 0}$ \\
\hline
\end{tabular}

\section{Research}

Therapists were asked it they had personally carried out occupational therapy specific research or had assisted anyone else to do so. Three did not respond and 63 (47\%) reported experience of research in one or both of these categories. Within the group of 48 who had assisted others with research, 32 had done so by completing a questionnaire and were disregarded; leaving 16 of 134 therapists (12\%) who had actually assisted with research.

Thirty therapists had personally conducted research and for ten this was part of their pre-registration education. Therefore 20 of 134 therapists $(15 \%)$ had conducted research at post-qualification level. Of these 20 therapists, 14 had a Diploma in Occupational Therapy representing $13.7 \%$ of the total number of diplomates while six had a degree representing $18.8 \%$ of graduates.

\section{Hours Worked}

All respondents indicated the hours they worked with 115 (84\%) working full time, and the remainder working part time. Those working part time were distributed throughout the grades. 


\section{Profession of Line Manager}

All but two respondents noted the title and profession of their line manager with the majority of respondents $84(62 \%)$ managed by an occupational therapist. The detail of line managers by grade of occupational therapist managed is shown in Table 4

Table 4 Profession of Line Manager According to Grade of Therapist Managed

\begin{tabular}{||r|r|r|r|r|r|r||}
\hline & \multicolumn{7}{|c|}{ PROFESSION OF LINE MANAGER } \\
\hline $\begin{array}{l}\text { Grade } \\
\text { of O T }\end{array}$ & O T & $\begin{array}{r}\text { Social } \\
\text { Worker }\end{array}$ & Nurse & Psychologist & $\begin{array}{r}\text { General } \\
\text { Manager }\end{array}$ & Total \\
\hline Basic & 11 & & 3 & & & $\mathbf{1 4}$ \\
\hline Senior 11 & 18 & & 4 & & & $\mathbf{2 2}$ \\
\hline Senior 1 & 35 & 3 & 16 & 4 & 1 & $\mathbf{5 9}$ \\
\hline Head 4 & 5 & & 1 & & & $\mathbf{6}$ \\
\hline Head 3 & 11 & & 6 & & 5 & $\mathbf{2 2}$ \\
\hline Head 2 & 2 & 1 & & & 3 & $\mathbf{6}$ \\
\hline Head 1 & 1 & & & & 1 & $\mathbf{2}$ \\
\hline OTHER & 1 & & 2 & & 1 & $\mathbf{4}$ \\
\hline TOTAL & $\mathbf{8 4}$ & $\mathbf{4}$ & $\mathbf{3 2}$ & $\mathbf{4}$ & $\mathbf{1 1}$ & $\mathbf{1 3 5}$ \\
\hline \hline
\end{tabular}

\section{Frequency of Supervision}

Five respondents did not receive supervision. Of the $132(96 \%)$ therapists who did receive supervision, $112(85 \%)$ were supervised by an occupational therapist. All 37 basic grade and Senior 11 staff were supervised by an occupational therapist, but 14 of them reported supervision as monthly or infrequently. The results by grade of the 131 staff who reported the frequency of supervision are shown in Table 5 ( one respondent did not report the frequency of supervision) . 
Table 5 Frequency of supervision received by grade of occupational therapist from occupational therapists and non occupational therapists.

\begin{tabular}{||l|r|r|r|r|r|r|r|r|r||}
\hline & \multicolumn{8}{|c||}{ FREQUENCY OF SUPERVISION } \\
\hline Grade of & \multicolumn{1}{|c|}{ Infrequent } & \multicolumn{2}{|c|}{ Monthly } & \multicolumn{1}{c|}{ Fortnightly } & \multicolumn{2}{|c|}{ Weekly } & \\
\hline O T & O T & No n & O T & Non & \multicolumn{1}{l|}{ O T } & Non & O T & Non & \multicolumn{1}{c|}{ Total } \\
\hline Basic & 3 & & 2 & & 1 & & 9 & & $\mathbf{1 5}$ \\
\hline Senior 11 & 3 & & 6 & & 10 & & 3 & & $\mathbf{2 2}$ \\
\hline Senior 1 & 10 & 2 & 18 & 4 & 19 & 1 & 3 & 1 & $\mathbf{5 8}$ \\
\hline Head 4 & & & 3 & 1 & 2 & & & & $\mathbf{6}$ \\
\hline Head 3 & 4 & & 7 & 2 & 3 & 3 & 2 & & $\mathbf{2 1}$ \\
\hline Head 2 & 1 & & 1 & 2 & & & & & $\mathbf{4}$ \\
\hline Head 1 & & 1 & 1 & & & & & & $\mathbf{2}$ \\
\hline Other & & & 1 & & & 2 & & & $\mathbf{3}$ \\
\hline Total & $\mathbf{2 1}$ & $\mathbf{3}$ & $\mathbf{3 9}$ & $\mathbf{9}$ & $\mathbf{3 5}$ & $\mathbf{6}$ & $\mathbf{1 7}$ & $\mathbf{1}$ & $\mathbf{1 3 1}$ \\
\hline \hline
\end{tabular}

EMPLOYER PROFILE

Working in an NHS Trust was the employer category cited by $123(90 \%)$ of the respondents. Of the remainder, three worked in local authority, four worked for a private charity, one was in private practice, one worked in a prison, two worked in special hospitals and three in other locations. Two thirds of therapists $(67 \%)$ worked for a mental health speciality while one third did not.

\section{Location of practice and client population}

All but one respondent classified their work both by its primary location and by the client population with whom they worked. The cross-tabulated results are shown in Table 6. The largest group, 45 (33\%) noted that their primary location was in hospital. However, if the ten therapists who identified community within the day facility category are added to the community team category they constitute a larger group with $48(35 \%)$ therapists. The 11 respondents in the 'other' category reported a variety of 
situations GP Practice; out patient clinic; hospital in the community; resource centre; residential homes; sheltered workshops and private homes. The largest group $52(38 \%)$ cited community mental health as their client population. Thirty (22\%) respondents worked in acute psychiatry with 13 working in rehabilitation and the same number in forensic settings.

Table 6 Location of practice by client population

\begin{tabular}{|c|c|c|c|c|c|c|}
\hline \multirow[t]{2}{*}{ Client Population } & \multicolumn{6}{|c|}{ Location of Practice } \\
\hline & Hospital & $\begin{array}{c}\text { Day } \\
\text { facility }\end{array}$ & $\begin{array}{c}\text { Community } \\
\text { team }\end{array}$ & Split site & Other & Total \\
\hline Acute psychiatry & 19 & 8 & 1 & 2 & & 30 \\
\hline Community & 2 & 10 & 31 & 7 & 2 & 52 \\
\hline Forensic & 11 & & & & 2 & 13 \\
\hline Substance Misuse & 1 & 3 & & & & 4 \\
\hline $\begin{array}{l}\text { Challenging } \\
\text { behaviour }\end{array}$ & 2 & & & & & 2 \\
\hline Eating disorder & 1 & & & & & 1 \\
\hline Continuing care & & & 1 & & & 1 \\
\hline Elderly mentally ill & 1 & 3 & 2 & 1 & 1 & 8 \\
\hline Rehabilitation & 3 & 3 & 3 & 3 & 1 & 13 \\
\hline Specialist & 5 & 1 & & & 4 & 10 \\
\hline Other & & 1 & & & 1 & 2 \\
\hline Total & 45 & 29 & 38 & 13 & 11 & 136 \\
\hline
\end{tabular}

\section{Client Age Range}

The majority, 122 (90\%), of practitioner worked with adults, 11(8\%) worked with elderly people, 3 (2\%) worked with children and adolescents and one did not respond.

\section{Time spent on clinical activity}

Of the hours worked whether full or part time, respondents indicated the percentage related to clinical activity, including patient contact and treatment related activities. One hundred and two (74\%) respondents spent more than half their time on clinical 
activity with the percentage tending to decrease the higher the grade of the occupational therapist as shown in the Table 7

Table 7. Percentage of Time Spent on Clinical Activity by Grade

\begin{tabular}{|l|r|l|r|r|r||}
\hline GRADE & \multicolumn{2}{|c|}{ PERCENTAGE OF CLINICAL TIME } & \\
\hline & $\mathbf{0}-\mathbf{2 4 \%}$ & $\begin{array}{l}\mathbf{2 5} \\
\mathbf{4 9 \%}\end{array}$ & $\mathbf{5 0}-\mathbf{7 4} \%$ & $\mathbf{7 5 - 1 0 0} \%$ & Total \\
\hline Basic & 1 & & 10 & 4 & $\mathbf{1 5}$ \\
\hline Senior 11 & 1 & & 9 & 12 & $\mathbf{2 2}$ \\
\hline Senior 1 & & 7 & 37 & 15 & $\mathbf{5 9}$ \\
\hline Head 4 & & 2 & 4 & & $\mathbf{6}$ \\
\hline Head 3 & 6 & 6 & 9 & 2 & $\mathbf{2 3}$ \\
\hline Head 2 & 3 & 3 & & & $\mathbf{6}$ \\
\hline Head 1 & 2 & & & & $\mathbf{2}$ \\
\hline Other & 4 & & & & $\mathbf{4}$ \\
\hline Total & $\mathbf{1 7}$ & $\mathbf{1 8}$ & $\mathbf{6 9}$ & $\mathbf{3 3}$ & $\mathbf{1 3 7}$ \\
\hline
\end{tabular}

\section{Occupational therapy and generic tasks}

Asked to estimate the proportion of their time spent in occupational therapy specific tasks, as opposed to generic tasks, 132 (95\%) responded. The results indicate that 91 (69\%) respondents spend between $25 \%$ and $74 \%$ of their time on occupational therapy tasks, with no clear pattern shown by grade. The results are shown in Table 8 .

Table 8 Percentage of Time Spent on Occupational Therapy Specific Activity by Grade

\begin{tabular}{||l|r|l|r|r|r||}
\hline \hline GRADE & \multicolumn{6}{|l|}{ PERCENTAGE OF TIME ON O TASKS } & \\
\hline & $\mathbf{0}-\mathbf{2 4 \%}$ & $\begin{array}{l}\mathbf{2 5} \\
\mathbf{4 9 \%}\end{array}$ & $-\mathbf{5 0}-\mathbf{7 4} \%$ & $\mathbf{7 5}-\mathbf{1 0 0} \%$ & Total \\
\hline Basic & 1 & 5 & 7 & 2 & $\mathbf{1 5}$ \\
\hline Senior 11 & 4 & 5 & 7 & 5 & $\mathbf{2 1}$ \\
\hline Senior 1 & 8 & 19 & 25 & 4 & $\mathbf{5 6}$ \\
\hline Head 4 & & 4 & & 2 & $\mathbf{6}$ \\
\hline Head 3 & 4 & 8 & 6 & 4 & $\mathbf{2 2}$ \\
\hline Head 2 & 1 & 1 & 3 & 1 & $\mathbf{6}$ \\
\hline Head 1 & 2 & & & & $\mathbf{2}$ \\
\hline Other & 3 & & 1 & & $\mathbf{4}$ \\
\hline
\end{tabular}




\begin{tabular}{||l|r|r|r|r|r||}
\hline Total & $\mathbf{2 3}$ & $\mathbf{4 2}$ & $\mathbf{4 9}$ & $\mathbf{1 8}$ & $\mathbf{1 3 2}$ \\
\hline
\end{tabular}

\section{Non-occupational therapy tasks}

Asked if they ever carried out tasks that would be considered outside the occupational therapy remit, 129 (94\%) responded, with 87 of 129 respondents (67\%) considering that they did. A total 104 examples of non-occupational therapy tasks were given and were categorised as shown in Table 9. In the cluster which involved medication, nine respondents reported some involvement from checking 'compliance' and 'giving advice' to 'issuing prescriptions'. Also in this category were 'explaining blood results to patients in relation to damage caused by alcohol' and 'testing urine for drugs'. Asked if they had received training for these non-occupational therapy tasks, $91(66 \%)$ of the total sample responded with 43 of $91(47 \%)$ practitioners reporting that they had been trained.

Table 9. Non-occupational therapy tasks undertaken

\begin{tabular}{||l|r|}
\hline TASK & NUMBER \\
\hline Escorting, Transport, Benefits, Assisting Other staff & 19 \\
\hline Counselling, Psychotherapy, family work & 18 \\
\hline Medication, blood results, testing urine & 11 \\
\hline Management & 10 \\
\hline Duty /on call /emergency & 9 \\
\hline Keyworker/ Co ordination & 9 \\
\hline General assessments & 8 \\
\hline Secretarial & 4 \\
\hline Control and restraint & 3 \\
\hline Organising social events & 3 \\
\hline Miscellaneous & 10 \\
\hline TOTAL & $\mathbf{1 0 4}$ \\
\hline
\end{tabular}




\section{Occupational therapy in mental health}

To obtain a picture of occupational therapy in mental health, respondents were given a number of options in a grid format about the interventions, models of practice and assessments they employed and with what frequency. With a choice of eight interventions, four models, three assessments, the opportunity to nominate other options and a choice of five frequencies including 'never', there were at least 75 choices. In contrast to other aspects of the questionnaire, this complex question produced a high number of non responses but many respondents did offer examples. Therefore, in presenting these results those who did not reply and who choose the 'never' category have been disregarded creating a different total for each topic.

\section{Interventions}

With a total score of 119 , leisure emerges as the most prevalent intervention. However, counselling is used most frequently on a daily basis by 59 respondents, representing $50 \%$ of those who used it and $43 \%$ of the total sample. Interventions scoring highly on a weekly basis were creative activities and anxiety management. Twenty-nine respondents (21\%) identified a total of 60 other interventions with anger management and cognitive behaviour therapy each nominated by six respondents and goal setting reported by four respondents. The remaining diverse titles were used by one to three respondents. The results are presented in rank order of total scores in Table 10. 
Table 10 Frequency of interventions used

\begin{tabular}{||l|r|r|r|r|r|r|r|r|r||}
\hline \hline Intervention & \multicolumn{9}{|c|}{ Frequency of Use } \\
\hline & \multicolumn{1}{|c|}{ Occasionally } & \multicolumn{1}{|l|}{ Monthly } & \multicolumn{2}{|l|}{ Weekly } & \multicolumn{1}{l|}{ Daily } & Total \\
\hline & No & \% & No & \% & No & \% & No & \% & No \\
\hline Leisure & 15 & 12.6 & 10 & 8.4 & 54 & 45.4 & 40 & 33.6 & $\mathbf{1 1 9}$ \\
\hline Counselling & 21 & 17.9 & & & 37 & 31.6 & 59 & 50.4 & $\mathbf{1 1 7}$ \\
\hline $\begin{array}{l}\text { Anxiety } \\
\text { Management }\end{array}$ & 24 & 20.5 & 7 & 6.0 & 65 & 55.6 & 21 & 17.9 & $\mathbf{1 1 7}$ \\
\hline ADL & 29 & 25.4 & 7 & 6.1 & 48 & 42.1 & 30 & 26.3 & $\mathbf{1 1 4}$ \\
\hline $\begin{array}{l}\text { Creative } \\
\text { activities }\end{array}$ & 15 & 13.4 & 8 & 7.1 & 67 & 59.8 & 22 & 19.6 & $\mathbf{1 1 2}$ \\
\hline Assertiveness & 32 & 30.5 & 15 & 14.3 & 51 & 48.6 & 7 & 6.7 & $\mathbf{1 0 5}$ \\
\hline Social skills & 25 & 23.8 & 18 & 17.1 & 47 & 44.8 & 15 & 14.3 & $\mathbf{1 0 5}$ \\
\hline Work & 21 & 20.8 & 17 & 16.8 & 44 & 43.6 & 19 & 18.8 & $\mathbf{1 0 1}$ \\
\hline \hline
\end{tabular}

\section{Models}

Thirty-two (23\%) respondents did not report using any model. In general, those therapists using models used more than one. The Model of Human Occupation (MOHO) emerged as the preferred model identified by 68 respondents representing $65 \%$ of those who used models and $50 \%$ of the total sample. Seven respondents identified eleven other models. One respondent used two models specific to substance misuse. The others were identified once; humanistic; analytical; cognitive behaviour therapy; problem solving; behavioural; rehabilitative; CPA standard assessment form; 'bits of Claudia Allen' and a 'mix of all sorts'. The results are presented in rank order of total scores in Table 11. 
Table 11 Frequency of models used

\begin{tabular}{||l|r|r|r|r|r|r|r|r|r||}
\hline \hline Model & \multicolumn{8}{|c||}{ Frequency of Use } \\
\hline & \multicolumn{2}{|c|}{ Occasionally } & \multicolumn{1}{l|}{ Monthly } & \multicolumn{1}{l|}{ Weekly } & \multicolumn{1}{l|}{ Daily } & \multicolumn{1}{c|}{ Total } \\
\hline & No & $\%$ & No & $\%$ & No & $\%$ & No & $\%$ & No \\
\hline MOHO & 24 & 35.3 & 4 & 5.9 & 14 & 20.6 & 26 & 38.2 & $\mathbf{6 8}$ \\
\hline COPM & 23 & 63.9 & 3 & 8.3 & 5 & 13.9 & 5 & 13.9 & $\mathbf{3 6}$ \\
\hline Reed/Sanderson & 10 & 30.3 & 4 & 12.1 & 6 & 18.2 & 13 & 39.4 & $\mathbf{3 3}$ \\
\hline Mosey & 7 & 33.3 & 3 & 14.3 & 4 & 19.0 & 7 & 33.3 & $\mathbf{2 1}$ \\
\hline
\end{tabular}

\section{Standardised Assessments}

Seventy four (54\%) respondents did not report using any standardised assessments.

The preferred assessment was the Canadian Occupational Performance Measure with 24 therapists (18\% of the total sample) using it. This is in contrast to 36 therapists ( $26 \%$ of the total sample) who used its companion the Canadian Occupational Performance Model. Similarly, 14 therapists reported using The Assessment of Motor and Process Skills (AMPS) and seven identified Occupational Case Analysis and Rating Scale OCARIS in contrast to the 68 therapists who used MOHO, the model from which these assessments were derived. Thirty-two respondents identified 53 other assessments. Of these the most frequently used were OCARIS, Beck's Depression and Anxiety Inventory six times and The Hospital Anxiety and Depression Scale five times. The results are presented in rank order of total scores in Table 12.

Table 12 Frequency of assessments used

\begin{tabular}{|c|c|c|c|c|c|c|c|c|c|}
\hline \multirow[t]{3}{*}{ Assessment } & \multicolumn{9}{|c|}{ Frequency of Use } \\
\hline & \multicolumn{2}{|c|}{ Occasionally } & \multicolumn{2}{|c|}{ Monthly } & \multicolumn{2}{|c|}{ Weekly } & \multicolumn{2}{|c|}{ Daily } & \multirow{2}{*}{$\begin{array}{r}\text { Total } \\
\text { No }\end{array}$} \\
\hline & No & $\%$ & No & $\%$ & No & $\%$ & No & $\%$ & \\
\hline COPM & 12 & 50.0 & 4 & 16.7 & 3 & 12.5 & 5 & 20.8 & 24 \\
\hline AMPS & 8 & 57.1 & 1 & 7.1 & 3 & 21.4 & 2 & 14.3 & 14 \\
\hline SOTOF & 4 & 50.0 & 1 & 12.5 & 2 & 25 & 1 & 12.5 & 8 \\
\hline
\end{tabular}




\section{Future issues in mental health}

The respondents gave up to three responses to the open question 'Thinking of the future, what you think are the three most important issues facing occupational therapists working in mental health?' Of the 137 respondents, 134 gave a first response, 132 gave a second response and 127 gave a third response. Many of these included two or more issues. Similar responses were grouped together and then further analysed and clustered. Their diversity made analysis and clustering more difficult and those issues identified infrequently were excluded.

The first, and largest, cluster was mentioned mainly as a third response. It included concerns about the loss of occupational therapists from leadership, management or supervisory roles, staff shortages, recruitment and retention of staff and lack of adequate funding for staff posts and burnout.

The second cluster focused mainly on educating other staff, managers and commissioners about the role, value and effectiveness of occupational therapy. This also included marketing and promotion, raising the profile, being involved in the development of new services and being 'able to measure outcomes and justify our existence to managers'.

The third cluster focused on clarifying and defining the core skills and role of occupational therapy in mental health. Various specific issues were mentioned, including respecting clients, holistic practice and the debates about the value of 
therapeutic activities; 'using activity based treatment rather than talking based treatment'

The fourth cluster included research, audit and evidence based practice. In each case there is a need for more time and funds to encourage and support these to happen; 'ensuring that interventions are effective and research based'. Also there is a need to develop and use standardised assessments and clinical outcome measures.

The fifth cluster concerned retaining a specialist role when working in multidisciplinary teams and 'not becoming just another keyworker' nor 'sliding into the blender'.

The sixth cluster concerned maintaining the established occupational therapy role, 'transferring concepts of selected activity to community settings' and 'the need for confidence and clarity in occupational therapy role'

The seventh cluster concerned various changes in service provision, including the shift towards community based work, specialist teams such as regional secure units and consultancy.

The last and smallest cluster focused on education of students and clinicians. 'The education of new occupational therapists does not seem to have kept up with the dramatic changes in mental health'. Practitioners do not have funding for, or access to, appropriate courses aimed at occupational therapists. 
The summary of the main clustering including the number of times each issue was mentioned as a first, second or third response and excluding infrequently identified issues in shown in Table 13

Table 13 Summary of Issues

\begin{tabular}{||l|r|r|r|r||}
\hline CLUSTERED ISSUES & \multicolumn{4}{l|}{ NUMBE OF RESPONSES } \\
\hline & $\mathbf{1}$ & $\mathbf{2}$ & $\mathbf{3}$ & TOTAL \\
\hline Lack of Occupational Therapy Management & 11 & 29 & 41 & $\mathbf{8 1}$ \\
\hline Marketing \& promotion & 33 & 23 & 24 & $\mathbf{8 0}$ \\
\hline Defining core skills and role & 36 & 16 & 13 & $\mathbf{6 5}$ \\
\hline Need for research, audit, evidence based practice & 20 & 18 & 27 & $\mathbf{6 5}$ \\
\hline Specialist v Generic role & 33 & 17 & 8 & $\mathbf{5 8}$ \\
\hline Maintenance of occupational therapy role & 21 & 16 & 8 & $\mathbf{4 5}$ \\
\hline Change to community care & 13 & 23 & 5 & $\mathbf{4 1}$ \\
\hline $\begin{array}{l}\text { Education for students and CONTINUING } \\
\text { PROFESSIONAL DEVELOPMENT }\end{array}$ & 2 & 6 & 20 & $\mathbf{2 8}$ \\
\hline Total issues & $\mathbf{1 6 9}$ & $\mathbf{1 4 8}$ & $\mathbf{1 4 6}$ & $\mathbf{4 6 3}$ \\
\hline
\end{tabular}

\section{Additional comments}

Eleven therapists provided additional comments and in contrast to other aspects of the survey, they were lengthy and personal. Some respondents suggested further important issues, while others explored items of personal relevance. The only new point to emerge related to comments from two respondents on the lack of questions on the ethnic background of the respondents.

\section{Discussion}

The response rate, at $68.5 \%$, was good and compared closely with Bartlow and Hartwig's (1989) survey of 136 Australian practitioners which achieved a 65\% response rate. In generalising the results of the survey to the larger population of occupational therapists in mental health in the UK caution must be exercised. The sample was derived from members of the AOTMH who have a special interest in 
mental health, which may be because they are experts in the area or novices seeking guidance. In either situation, they may not be representative of other practitioners. However, in the absence of a more representative sample and in view of the paucity of published data, the results provide a useful foundation for comparison and further study.

\section{Employment pattern}

Thirty- nine percent of the practitioners have worked for less than 5 years in mental health and $68 \%$ for less than 10 years, confirming their relative inexperience as occupational therapists. Just over half of the practitioners (54\%) had only worked in mental health, with others working in other areas for less than 2 years before moving into mental health. This information will be relevant to those managers responsible for recruitment.

The reasons stated for working in mental health are interesting. Variety and diversity are valued, as are opportunities for carrying out treatment as well as assessment. Practice in mental health is viewed as interesting and rewarding due to greater informality, autonomy and creativity. Thus, it could be postulated that it is those very characteristics which attract occupational therapists to mental health which are those later lead to role conflict and confusion.

\section{Additional training}

Ninety-one percent of the practitioners reported additional training, some was occupational therapy specific, but much was generic. It may be that members of AOTMH are more motivated than others to extend their skills. The majority of 
respondents also identified areas for further training, many about new areas of the profession or revising existing occupational therapy knowledge. Taken together these findings tend to suggest that in their quest for personal development occupational therapists have gone outside the profession, perhaps due to the shortage of occupational therapy specific courses or the external pressure to generic working.

While it would be churlish to suggest that occupational therapists cannot learn from other professions, the emphasis on general training adds to overall quandary about the scope of occupational therapy practice. Respondents identifying important issues facing the profession noted the lack of appropriate courses for occupational therapists. Perhaps the time is now right to deepen knowledge about occupational therapy. Although obtaining funding for this may remain a problem. The provision of more occupational therapy specific Continuing Professional Development (CPD) and Master's degrees in occupational therapy could do much to address this. With the revision of the Professions Supplementary to Medicine Act 1960 with its likely mandating of CPD, it has already been suggested that the relevance of CPD to the profession may have to demonstrate if its intention is to ensure competence to practise (Craik, 1997).

\section{Research}

Less than half of the respondents had participated in research and closer examination reduced the number actively involved in research, not connected to obtaining a qualification, to $15 \%$. A slightly higher percentage of therapists educated to degree level rather than diploma level had personally conducted research. While this can be considered disappointing at present, the impact of graduate entry to the profession and 
the trend for therapists with diplomas to upgrade their qualification can also be seen. However, much of the evidence from this research remains to be published. The respondents are aware of need for research, audit, evidence-based practice and funding to facilitate these, recognising this as one of the issues facing the profession.

\section{Supervision}

One- third of the respondents were not managed by an occupational therapist and while this may be acceptable for head, and perhaps Senior 1, therapists, it is concerning that three basic grade and four senior 11 occupational therapists were managed by non-occupational therapists. More reassuring was the high number (96\%) of respondents who received supervision $85 \%$ from another occupational therapist.

For established professionals the College of Occupational Therapists (1997) suggests monthly supervision. That frequency or better was received by 19 of the $22(86 \%)$ Senior 11 and by 46 of the 58 (79\%) Senior1occupational therapists. For new practitioners, the College suggests weekly supervision which was received by 9 of the 15 basic grade therapists. It is especially regrettable that the six basic grade therapists whose frequency of supervision fell below the standard suggested by the College, were all supervised by an occupational therapist.

\section{Area of practice}

Considering both location of practice and client population, the principal area of practice was community mental health which reflected one the main themes identified in the literature (Craik, 1998). Forensic psychiatry was another major topic in the 
literature (Craik, 1998) but this was less obviously identified in this study with 13 respondents citing it as an area of practice. Eleven respondents worked with elderly people which again did not reflect the position of dementia as a major theme from the literature (Craik, 1998). However, the population surveyed were members of the AOTMH and those therapists with interest in elderly people may be members of the Specialist Section for Elderly People.

\section{Occupational therapy tasks}

Considering the estimated percentage of time the respondents spent in nonoccupational therapy specific tasks and the variety of these tasks, several questions arise. With a recognised national shortage of occupational therapists it is interesting to speculate why so many spend so much time in non-occupational therapy tasks.

Irrespective of the profession of the line manager, it is surprising that so many therapists report time spent in clerical and assistant duties. Effective management of expensive professional staff should preclude this. However, this finding adds weight to the issue which the respondents recognised as the main one facing the profession in the future, the loss of occupational therapists from leadership, management and supervisory roles.

Time spent on activities such as counselling and keyworking may be attributed to the move to generic working especially in community mental health teams and while this raises issues of philosophy and professional practice, it has been argued that occupational therapists are well qualified to do this (Miller and Robertson, 1991). However, respondents noted this as an issue for the future and they were concerned 
not to become deskilled generic mental health workers but to retain a specialist role in the multidisciplinary team.

Of particular concern are the 11 respondents involved with medication, explaining blood results and testing urine. Without more detail of circumstances, it is difficult to be certain, but whether or not they received training for these tasks, it seems likely that many of these therapists were contravening the Code of Ethics and Professional Conduct (COT, 1995, p 12 ) which states that 'occupational therapists shall only provide services and use techniques for which they are qualified by education or experience, and are within their professional competence'. While this is clearly the responsibility of the individual occupational therapists, it also reinforces the need to educate others about the role of occupational therapy; one of the issues the respondents registered as important for the future of the profession.

\section{Interventions, models and assessments}

In contrast to the literature, (Craik, 1998) work rehabilitation did not feature highly in the interventions chosen by the occupational therapists, being the least favoured of the eight options offered. Leisure was the most prevalent when considering total scores, however, counselling was used most frequently on a daily basis with creative activities and anxiety management achieving high scores as interventions used weekly. There are similarities to the results of Meeson (1998) who found that supportive counselling and anxiety management were the most frequently chosen interventions over a 4 week period by 12 senior 1 occupational therapists in community mental health teams in south east England. 
The predominance of anxiety management and especially counselling may be linked to the availability and uptake of training opportunities in counselling. The case for considering counselling as a rightful aspect of occupational therapy has been advocated by Job et al (1997). However, respondents noted a cluster of issues focused on clarifying and defining the core skills and role of occupational therapy in mental health and the debate about the value of therapeutic activities and 'talking' therapies.

Three-quarters of the respondents reported using models to guide intervention with the Model of Human Occupation being the most prevalent, reported by half the sample. Others were used less frequently. Less than half of the occupational therapists reported using standardised assessments with the Canadian Occupational Performance Measure the most frequently used of a wide variety. However, respondents also recorded a need to develop and use standardised assessments and outcome measures as important issues reinforcing their identified need for more occupational therapy specific training.

\section{Conclusions}

In some respects it is disheartening to realise that the major problems in mental health identified by Barris and Kielhofner (1986) in the USA, deficiencies in role definition, unifying theory and research validating the profession - are still present in the UK. Similarly, Bartlow and Hartwig (1989) in Australia noted lack of consensus about the pattern of service delivery, scope of practice and the use of assessments which were issues identified in this study. 
Nevertheless, the respondents in this study retain enthusiasm for, and commitment to, occupational therapy in mental health. They demonstrate concern about moves to generic working, a wish to remain true to the core principles of the profession, an understanding of the need for outcome measures and evidence based practice to validate interventions. There is an eagerness to learn more about occupational therapy. While the number of therapists actively involved in research is small there is a larger number aware of its potential and convinced of the need for more.

This study has provided data, not only to inform the position paper but also, to enable individual occupational therapists and managers to be informed about the current position and to allow them to compare their practice and service with others. This is a valuable foundation if occupational therapists in mental health are to bring about the changes which will be necessary to ensure a vibrant future for the profession and its clients. 


\section{Acknowledgements}

The authors would like to thank the members of the Association of Occupational Therapists in Mental Health who contributed to the study; the College of Occupational Therapists for establishing the project; Chris Austin and Donna Schell of the Project Working Group; Dominique Le Marchand and colleagues at the College and the reviewers of this article whose timely, comprehensive and supportive responses allowed it to be published so promptly. 


\section{REFERENCES}

Barris R, Kielhofner G (1986) Beliefs, perspectives and activities of psychosocial occupational therapy educators. American Journal of Occupational Therapy, 40(8), $535-41$.

Bartlow P, Hartwig C (1989) Status of practice in mental health : assessment of frames of reference. Australian Occupational Therapy Journal, 36(4), 180-92.

Bonder B R (1987) Occupational therapy in mental health: crisis or opportunity? American Journal of Occupational Therapy, 41(8), 495-9.

College of Occupational Therapists, (1995) Code of Ethics and Professional Conduct. College of Occupational Therapists, London

College of Occupational Therapists (1997), Standards, Policies and Procedures SPP 150 (A) Supervision in occupational therapy, College of Occupational Therapists, London.

Craik C, (1997) Review of the Professions Supplementary to Medicine Act 1960: implications for occupational therapists, British Journal of Occupational Therapy, 60 (7), 305-8.

Craik (1998) Occupational therapy in mental health: a review of the literature, British Journal of Occupational Therapy, 61(5),

Job T, Broom W, Habermehl F (1997) Coming out! Time to acknowledge the importance of counselling skills in occupational therapy. British Journal of Occupational Therapy, 60(8), 357-8.

Kleinman B L (1992) The challenge of providing occupational therapy in mental health. American Journal of Occupational Therapy, 46(6), 555-7.

Meeson B, (1998a) Occupational therapy in community mental health, part 1: intervention choice, British Journal of Occupational Therapy, 61(1), 7-12.

Meeson B, (1998b) Occupational therapy in community mental health, part 2: factors influencing intervention choice, British Journal of Occupational Therapy, 61(2), 5762.

Miller V, Robertson S (1991) A role for occupational therapy in crisis intervention and prevention. Australian Occupational Therapy Journal, 38(3), 143-6.

Paul S (1996) Mental health: an endangered occupational therapy speciality. American Journal of Occupational Therapy, 50(1), 65-8. 